\title{
Innovation in Reviewing using Internet of Things
}

\author{
Maryam Ashtari Mahini
}

\begin{abstract}
Learning is not only happening at schools, but also done out of schools even during the students' free time such as resting on the bed or on the chair. These times can be managed in order to review courses based on Ebbinghaus forgetting curve. Lack of reviewing system, having trouble with making an accurate review plan, checking the review plan and not spending time on review, cause the students to forget courses soon and easily. This proposed system which is self-regulatory, helps students to review their courses while resting, through adapting internet of things technology, cloud computing and mobile learning. IOT sensors monitor the student' situation and Gathered data is sent to the cloud server, stored and then analyzed to find out if the student is resting or not. Reviewcourses are stored in a cloud server, selected according to reviewcourses-priorities which is made based on Ebbinghaus forgetting curve and then sent to the student's cellphone and played without the student's involvement and effort. Our assumption is that by employing internet of the things technology in order to review courses in the resting time, learning level will increase. Allowing the students to devote more time to review, engaging the students, selflearning, continuous learning process, reduction in waste of talent and time, loss of learning motivation and memory are the system's benefits.
\end{abstract}

Keywords-Internet of the things, Education, Learning, Ebbinghaus forgetting curve, Review, resting time.

\section{INTRODUCTION}

Internet of the Things (IOT) is a paradigm that is based on the idea of pervasive presence around us of interconnected objects such as Radio frequency identification (RFID) tags, sensors, actuators, cellphones, etc., which are uniquely addressed, have interaction based on standard protocols [27] in order to reach their common goal [39], bring happiness to life [37], enable innovative application [31] and share data over the networks, with or without human intervention [22]. All these sensing and actuating objects [31] are managed from the web, provide real time data that is sent to the internet to build a smart system [14] and interaction between people [2]. IOT technology allows physical entities and physical phenomenon to communicate with each other [14]. IOT was initially introduced in 1999 by Kevin Ashton in the MIT Auto-Id Labs by linking RFID information to the internet [21], [33].

RFID tags are attached to the objects which can be identified by RFID reader, can bridge between the physical world and the digital world [21], [37]. RFIDs is a wireless

Maryam Ashtari Mahini is with the Department of computer engineering, Science and Research Branch, Islamic Azad University, Tehran, Iran communication technology, can be read away from the line of sight, use radio waves to identify objects precisely and track them in real time [28], [38]. Equipping all objects with identifiers, wireless connectivity and managing by computers are the concept of IOT [33]. Sensor technology both enables computers to observe, identify and understand the world without the human involvement and as a result, reduces loss, waste and cost [30]. All the objects should possess one or more sensors to monitor a specific condition such as location, vibration, motion, temperature and etc. to provide some new information to system and people [33].

Using innovative technologies such as IOT in education has the potential to change the learning process. Learners can acquire knowledge in a new, natural and efficient manner match with their needs and expectation and training can become a part of daily activities. Easy and quick access to the educational resources, transforming learning from passive to active, providing formal and informal learning, reporting learning achievements, tracking learning progresses and attendance in the classroom, developing an accurate student's profile, providing individual personalized training plan, saving time to carry out some routine daily activities, enabling teachers to focus on the process of training, informing teachers when some students have difficulties while doing tasks, creating a user friendly environment for disabled students, providing tools for easy and quick creation of contents, recording and sharing learning activities in the classroom automatically, supporting collaboration and making decisions based on the collected data from IOT sensors are some opportunities that IOT provides for education[1].

IOT bearing in mind the concept of "ubiquitous computing" in which technology is around users, without getting involved in their everyday life and enables them to interact with technology [20], [38]. Research efforts aim at exploitation of UMI (UbiComp, MobiComp and IOT) in STEM education in order to use them as both subjects of educations and facilitators of the educational processes [26]. [19] investigates the impact of UMI on education, especially Mobile learning which offers some facilities to get knowledge and skills, in an ubiquitous, personalized manner, Learnercentered learning experience, anytime and anywhere due to its personalization, ubiquity, context-awareness, interactivity, multiple media representation and social-media connectivity. Authors in [2], find out that the potential of Ubiquitous learning is in increasing access to learning contents, anytime 
and anywhere. The origin of IOT is derived from Ubiquitous computing in which computers are available in physical world but invisible to users. Rapid computers, communication technology and especially IOT is becoming increasingly growing concept, due to spreading smart phone, decreasing connection technology, growing broadband internet access and producing more devices with Wi-Fi capabilities and sensors [34],that impacts not only on how we live but also on how we work [34] and how we learn [6], [37].

IOT has some applications in classroom environment monitoring [7], [17], [27], [13], [1], [20], [18], [41], [11], [24], disabled students education [40],[37], students' healthcare and food [4], [27],students 'transportation [27],[13],[4], assessment[27],[4], [11], school security[27],[1],[29], [4], [23], pedagogy[27],[13], [37], [4], [25], [28], [2], [6], [9], [11], [42], saving energy at school[13], [4], and other applications which are discussed in [15], [27], [32],[3], [1], [36], [8], [12], [11]. Profound changes in teaching, management, experimental training, campus building and etc., are provided by deploying IOT in institutions of higher learning [37]. In this paper, we focus on pedagogy.

This research provides us an opportunity to study how IOT can be adopted to manage the students 'resting time in order to review courses. This is a self-regulatory system that controls itself, rather than students make sure that review rules are obeyed. We believe that pedagogy based on IOT technology can help the digital-born students to improve their educational achievement. This paper is structured as follows: First, an overview of IOT, RFID, sensors, exploiting of IOT in education, ubiquitous computing, and IOT applications especially in education are outlined. Then, the theoretical background about using IOT in education is outlined. Following, the proposed methodology of using IOT to help students to review courses is described. After that, the comparison between this proposed system and the other related researches are presented, followed by conclusions.

\section{LITERATURE REVIEW}

Authors in [9] believe that IOT based educational technology can help the students to have personalized, rich and interactive learning, anytime and anywhere. They present a prototype for primary science education in order to help the students to learn new ideas based on their own understanding and find out the truth, record their observation and draw conclusion. Temperature, humidity and light sensors collect real time data about the growing process of beans and then gathered data and captured images are displayed on the students' friendly graphical interface cellphone. In [28], the interaction based on IOT is provided between two laboratories. Students in under-resourced school laboratory instruct the remote robotic arm to do the experiment in wellresourced school laboratory.[21] proposes an interactive whiteboard that transfers the courses from teacher's tablet to students' tablet and video projector by integrated mechanism of any related things and IOT technology. In [8], author presents deploying IOT in providing smart education in order to save time of teacher, know about the students 'learning capabilities and measure the performance of the students. Authors in [36] have developed a communication platform in which Students report their school problems by their cellphone to a center bank to make accurate and right decisions. Authors in [25] discuss the IOT opportunities in developing students 'computational thinking. It allows youth to build a plant monitoring application to get notification of the plant on their cellphone via Bluetooth.

In one of Thailand school, using IOT technology, temperature, humidity and lightening of classrooms are measured, stored, be visible to students for planting bean in their classroom. These measurements are displayed on students 'mobile screen in an attractive and suitable interface [9]. The purpose of [6] is building "Ohm law circuit" based on IOT which can read circuit's voltages, currents and etc. in an automated laboratory. It can be programmatically controlled over internet. It also presents a system in which sensors can measure natural phenomenon such as humidity, light, temperature and etc. not over local sensor network but on gateway where sensor unit is not visible to end users. Devices can be accessed over IP address or Broker service.

\section{MethodOLOGY}

The purpose of this paper is to integrate IOT technology into Ebbinghaus forgetting curve to review courses during students' resting time. In other words, when IOT sensors diagnose that student is resting on the review-chair, system selects and plays a review course based on review-time table which was provided according to Ebbinghaus forgetting curve.

By using this review system, all courses by considering Ebbinghaus forgetting curve can be reviewed in less than 144 minutes in a day .Although it is noticeable time, memory doesn't lose information as time goes by and help students to retain much of information. The system allows students to have a choice of reviewing or not and as a result, reduces level of students 'anxieties. The teacher gives emotional and cognitive feedback on answering questions, in order to increase student's feeling of being capable. Enhancing feeling of competence is provided by the questions which are asked at the end of each review. The system facilitates social network communication among students, their peers and their teacher. So this system provides autonomy, competence and relatedness which are leaded to increase learning motivation [16]. Assume that each today's course needs at most 15 minutes to be reviewed, each yesterday's course needs 12 minutes, each one week before 's course needs 9 minutes, each one month before 's course needs 7 minutes and each three months before 's course needs 5 minutes to be reviewed. Consider that student learns 3 courses each day. So, reviewing all courses are taught today needs at most 45 minutes, all yesterday's courses needs 36 minutes, all one week before 's courses needs 27 minutes, all one month before 's courses needs 21 minutes and all three months before 's courses needs 
15 minutes. In other words, reviewing today's, yesterday's, before' courses takes at most 144 minutes (table 1). one week before's, one month before's and three months

TABLE I:

REVIEW-COURSES-PRIORITIES

\begin{tabular}{lcccc}
\hline Courses category & Associated category & $\begin{array}{c}\text { Course- } \\
\text { review- } \\
\text { priority }\end{array}$ & $\begin{array}{l}\text { time needed } \\
\text { according to } \\
\text { each category }\end{array}$ & All review time needed \\
\hline Courses haven't been reviewed & --- & 0 & --- & --- \\
Courses have been reviewed once & First Review & 1 & $15 * 3=45$ min & 45 min \\
Courses have been reviewed two times & Second Review & 2 & $12 * 3=36$ min & $45+36=81 \mathrm{~min}$ \\
Courses have been reviewed three times & Third Review & 3 & $9 * 3=27$ min & $81+27=108 \mathrm{~min}$ \\
Courses have been reviewed four times & Forth Review & 4 & $7 * 3=21 \mathrm{~min}$ & $108+21=129 \mathrm{~min}$ \\
Courses have been reviewed five times & Fifth Review & 5 & $5 * 3=15 \mathrm{~min}$ & $129+15=144 \mathrm{~min}$ \\
\hline
\end{tabular}

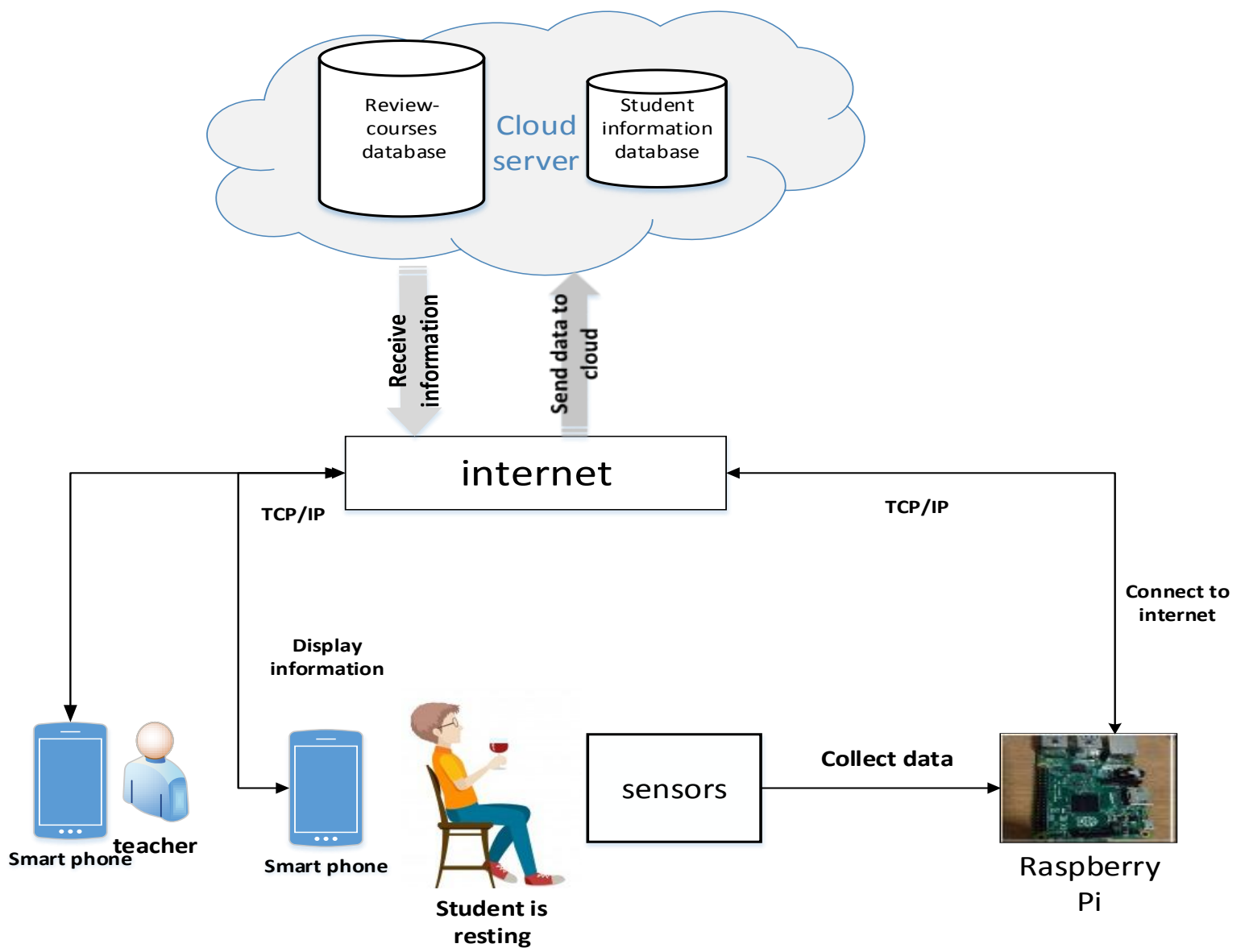

Fig. 1: Overall proposed system

The operation of this proposed system is governed by functionality of IOT technology and Ebbinghaus forgetting curve (see figure 1).

System has some IOT sensors that collect information about students. These sensors are controlled by a Raspberry Pi computer which is small, low cost and connected to the internet through a wireless USB adapter to upload the collected data to the cloud in order to use when necessary. Until the system diagnose that the student is resting on the review-chair, it plays review-courses. It will be continuing until the system diagnose that the student isn't resting. The cell phone software system selects one of video / audio reviewcourses based on a review-course-priority and play it on the screen of student's cell phone. As it can be seen, the system consists of some sensors, internet connection, courses, cloud servers and a software which are described in the following.

\section{A. Sensors}

RFID technology allows microchips to transmit identification numbers of objects to a reader through wireless communication in order to be identified, tracked and monitored automatically [14]. IOT sensors (Tag readers) are able to sense, gather and share through internet to process and analyze for different goals. In this research, the student's tag is read by a sensor which monitors, controls and gathers real time data about the student. The student has a tag. Gathered data is 
sent to the cloud server by internet connection, stores and analyzed in a cloud server. If sensors diagnose that the student is resting on the review-chair, so the cellphone software plays one of review-courses. This proposed system is motivating because the student has autonomy to stop resting (leave the review-chair) when is needed [16].

\section{B. Teacher}

In IOT-based education, teachers play the role of facilitators who sets project goals, provides resources and gives the students supporting feedbacks [6]. In this proposed system, teachers have to prepare video / audio review courses related to each review and each course. Today's review course should be at most 15 minutes for each course and yesterday's review course should be at most 12 minutes for each course and so on (see table 1). These review-courses should cover all main parts of courses. There are some software tools to help teachers in the production of interactive video lesson [10] if they are needed. They are stored in a cloud server and played when the student is resting on the review-chair. After each review process, the cellphone software system can provide a review-report related to each student to inform the teacher about student review activities. So, in this scenario, role of the teacher is taken into account by firstly playing their preprepared review-courses due to being familiar to their students and secondly receiving review-reports in order to give feedback to the students.

\section{Cloud Server}

Student's personal information, review information and video/audio review-courses are stored in a cloud server. Student's personal information is used for identifying students. Review information indicates how many revision related to each course have been done. It also saves priority of courses. Video/audio review-courses include important materials of each courses that were prepared by their teacher. All of these data can be shared with student's teacher and peers in social network in order to increase relatedness, competence and as a result, learning motivation [16]. Also they can be reviewed everywhere and every time from any application which are accessible. These data can be sent to the cloud when the state changes, instead of updating periodically [20].

\section{Software}

Making Plans for reviewing courses is difficult because it needs amount of time, dedication and precision. Also students don't know how to make. In this paper, an intelligent review system is proposed based on forgetting curve. In the following, its flowchart (figure 2) is represented and explained

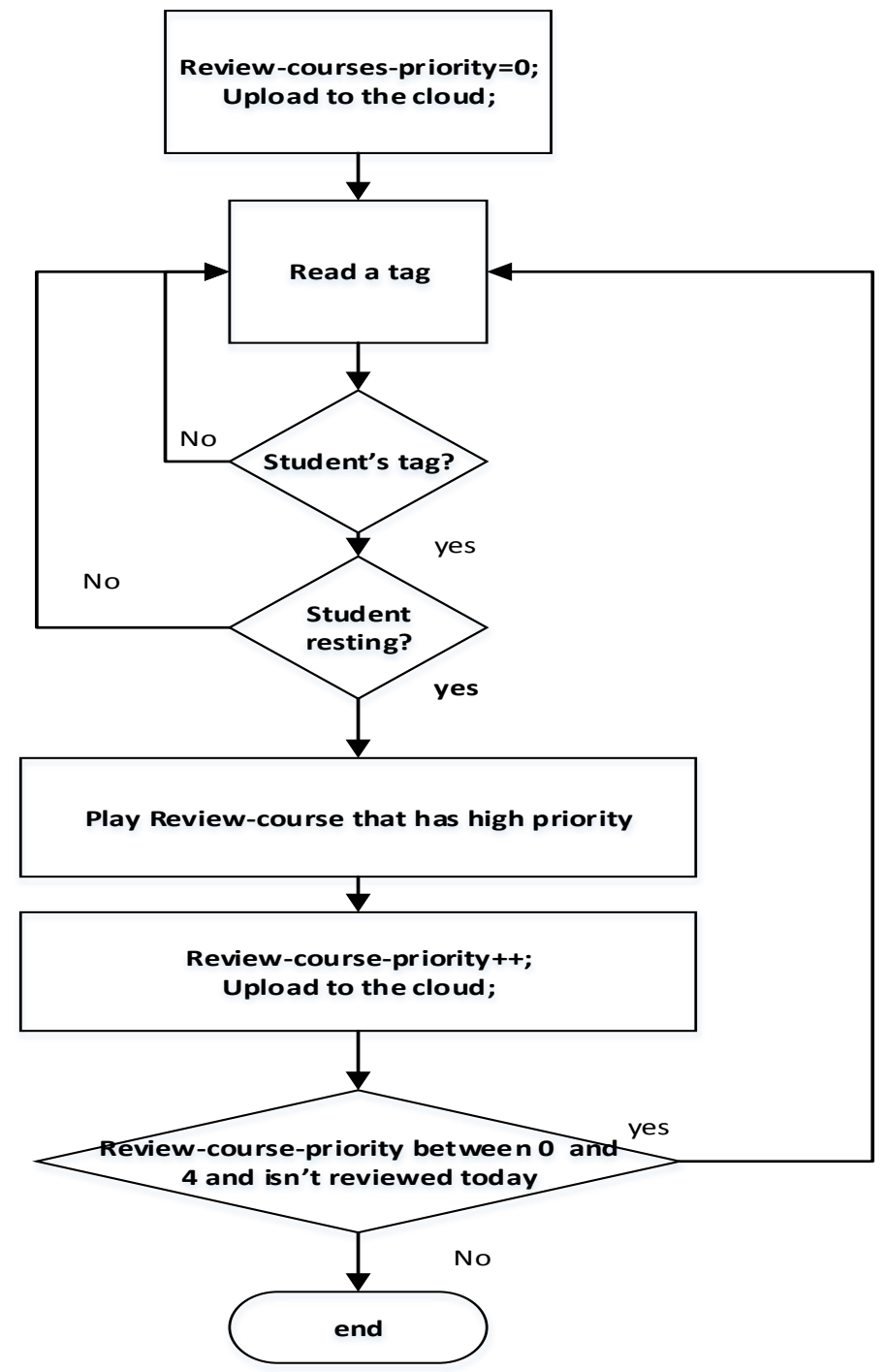

Fig. 2: Flow chart

System associates courses priorities with numbers. For example, today's courses haven't reviewed, are associated with highest priority. Zero is used for highest priority number. If a review-course has zero priority, it means that they should be recalled and reviewed before the others. After first review, the priority changes from zero to one. It shows that it has reviewed once. For courses with the same priority, software play one of them randomly. Every video/audio review course can be reviewed once in a day, not more. Next time, if there isn't any course with the same priority, the system selects the course with highest priority. All priorities are stored in a database. Priority number is between 0 and 5. So no course is needed to review more than 5 times. Base date is today. It means that if the teacher teaches a course today, third revision should be done one week after today and fourth revision, one month later (Table 1). At the end of each review course, three relevant questions which are prepared by the teacher, are asked in order to assess student's learning and enhance their motivation and competence feeling. 


\section{COMPARISON AND CONCLUSION}

Using artificial intelligence methods provide freedom of action for students and lead them to gain their learning goals [5]. The proposed system, has been based on IOT and Ebbinghaus forgetting curve. Student information has been collected by sensors and uploaded in the cloud. Reviewcourses which have been stored in the cloud, then selected based on a review-course-priority table and after that played on the student's cellphone during his/her resting time. As review reports can be shared with teacher and peers of the student, so they can interact and compete with each other. Also teachers can assess students based on their review report and exam results.

Although this proposed system has some limitation in inability for all courses and difficulties for teachers to provide a lot of review-courses related to each course, it provides some opportunities for all of the students in managing their resting time, helping them to review courses without tension and providing prerequisites, reviewing based on an accurate review-courses-priorities plan, reviewing without their involvement and providing order, discipline and continuance in reviewing courses which are taught by their own teacher and so are familiar to them. Therefore, it is expected that by exploiting IOT in reviewing courses, learning motivation, satisfaction and achievement of students increase.

\section{REFERENCES}

[1] Z. Tianbo, "The internet of things promoting higher education revolution", Multimedia Information Networking and Security (MINES), 2012 Fourth International Conference on. IEEE, 2012. https://doi.org/10.1109/MINES.2012.231

[2] J. Gómez, J.F. Huete, O. Hoyos, L. Perez and D. Grigori, "Interaction system based on internet of things as support for education “, Procedia Computer Science 21 (2013): 132-139. https://doi.org/10.1016/j.procs.2013.09.019

[3] I. Lee and K. Lee, "The Internet of Things (IoT): Applications, investments, and challenges for enterprises", Business Horizons 58.4 (2015): 431-440. https://doi.org/10.1016/j.bushor.2015.03.008

[4] M. Selinger, A.Sepulveda, and J.Buchan, "Education and the Internet of Everything, How Ubiquitous Connectedness Can Help Transform Pedagogy". Cisco Consulting Services and Cisco EMEAR Education Team.,2013

[5] A.S. Drigas and R.E. Ioannidou, "A review on artificial intelligence in special education", World Summit on Knowledge Society. Springer, Berlin, Heidelberg, 2011.

[6] V. Vujovic and M. Maksimovic, "The Impact of the Internet of Things on Engineering Education", ICOFE (2015):

[7] W.Runathong,W.Wongthai and S.Panithansuwan,"A System for Classroom Environment Monitoring Using Internet of Things, Cloud Computing", International Conference Information Science and Applications.Springer,Singapore, 2017. https://doi.org/10.1007/978-981-10-4154-9_84

[8] J. Kaur and K. Kaur, "Internet of Things: A Review on Technologies, Architecture, Challenges, Applications, Future Trends", International Journal of Computer Network and Information Security 9.4 (2017): 57.

[9] P. Putjorn, C.S. Ang and D. Farzin, "Learning IoT without the IEducational Internet of Things in a Developing Context", Proceedings of 2015 Workshop on Do-it-yourself Networking: an Interdisciplinary Approach. ACM, 2015. https://doi.org/10.1145/2753488.2753489

[10] N. Angelova, G. Kiryakova and L. Yordanova, "Flipped Classroom-a pedagogical model for active learning", Proceedings of 9th International Balkan Education and Science Conference, 2014.
[11] G.A.R. González, “ Evaluación de introducción de Internet de objetos en espacios de aprendizaje", Doctoral dissertation, Universidad Carlos III de Madrid, 2010

[12] Y.Yang, "Research and Design of the teaching platform architecture based on IOT", International Journal of Computer Science and Network Security (IJCSNS) 12.5 (2012): 103.

[13] M.W. Sari, P.W. Ciptadi, and R.H. Hardyanto, "Study of Smart Campus Development Using Internet of Things Technology", IOP Conference Series: Materials Science and Engineering. Vol. 190. No. 1. IOP Publishing, 2017. https://doi.org/10.1088/1757-899X/190/1/012032

[14] J.S.He, S. Ji, and P.O Bobbie, "Internet of Things (IoT)-based Learning Framework to Facilitate STEM Undergraduate Education." Proceedings of the SouthEast Conference. ACM, 2017. https://doi.org/10.1145/3077286.3077321

[15] G.R.González,M.M. Organero, and C. D. Kloos,"Exploring NFC for supporting mobility in learning scenarios." (2008).

[16] M. Rosli, I.Ismail, R.M. Idrus and A.A. Ziden, "Adoption of mobile learning among distance education students in University Saints Malaysia.", International Journal of Interactive Mobile Technologies (iJIM) 4.2 (2010): 24-28.

[17] Y.H.Hung and R.I. Chang. "The implementation of IoT for cloud system in industries-educational IoT case." Control, Automation and Robotics (ICCAR), 2017 3rd International Conference on. IEEE, 2017. https://doi.org/10.1109/ICCAR.2017.7942792

[18] M.Kusmin,M.Saar,M.Laanpere and M.J.Rodríguez-Triana,"Work in progress Smart schoolhouse as a data-driven inquiry learning space for the next generation of engineers." (EDUCON), 2017 IEEE.

[19] A.Mavroudi,A.A.Economides, O.Fragkou,S.A.Nikou,M.Divitini,M.Giannakos, A.Kameas,"Motivating students with Mobiles, Ubiquitous applications and the Internet of Things for STEM (MUMI4STEM).”(EDUCON), 2017 IEEE.

[20] D.Palma,et al. "Internet of Things example:Classrooms access control over near field communication.” Sensors 14.4 (2014): 6998-7012 https://doi.org/10.3390/s140406998.

[21] F.CH.Chang, D.K. Chen, and H.Ch. Huang. "Future Classroom with the Internet of Things A Service-Oriented Framework." J. Inf. Hiding Multimedia. Signal Process6 (2015): 869-881.

[22] B.Burd, et al. "The Internet of Things in CS Education: Current Challenges and Future Potential." Proceedings of the 2017 ACM Conference on Innovation and Technology in Computer Science Education. ACM, 2017. https://doi.org/10.1145/3059009.3081331

[23] B.Anbarasan, "The Internet of Things-The Thing to Watch." (2017).

[24] A.Njeru, M.M. Omar and S.Yi. "IoTs for capturing and mastering massive data online learning courses." Computer and Information Science (ICIS), 2017 IEEE/ACIS 16th International Conference. IEEE, 2017.

https://doi.org/10.1109/ICIS.2017.7959975

[25] M.TISSENBAUM, et al. "Off the Screen, and Into the World of Everyday Objects: Computational Thinking for Youth with the Internet of Things." Siu-cheung KONG the Education University of Hong Kong, Hong Kong (2017): 145.

[26] K.T.Delistavrou and A.D.Kameas. "Exploring ways to exploit UMI technologies in STEM education: Comparison of secondary computer science curricula of Greece, Cyprus and England.” (EDUCON), IEEE, 2017.

[27] N.Dlodlo, "The internet of things technologies in teaching, learning and basic education management." (2012).

[28] N.Dlodlo and Andrew C. Smith. "Internet-of-things in remote-controlled laboratories." (2011).

[29] Z.Mirza and M.N. Brohi. "An in-depth analysis on integrating campus radio frequency identification system on clouds for enhancing security." (2013).

[30] K.Ashton, "That 'internet of things' thing." RFiD Journal22.7 (2011).

[31] J.Gubbi, et al. "Internet of Things (IoT): A vision, architectural elements, and future directions." Future generation computer systems 29.7 (2013): 1645-1660. https://doi.org/10.1016/j.future.2013.01.010

[32] B.Burd, et al. "The Internet of Things in CS Education: Current Challenges and Future Potential." Proceedings of the 2017 ACM 
Conference on Innovation and Technology in Computer Science Education. ACM, 2017.

https://doi.org/10.1145/3059009.3081331

[33] https://www.cisco.com/c/dam/en_us/solutions/trends/iot/introduction_to _IoT_november.pdf

[34] J.Morgan,"A Simple Explanation of Internet of Things"Forbes Leadership,online resource accessed 29.09 (2014): 2015.

[35] G.Kiryakova,L.Yordanova and N.Angelova. "Can we make Schools and Universities smarter with the Internet of Things?" TEM journal technology education management informatics 6.1 (2017): 80-84.

[36] N.Dlodlo, J. P. Tolmay, and P. Mvelase. "Handing over ownership of schools to learners." (2012).

[37] L.Lenz, A. Pomp, T. Meisen and S.Jeschke, "How will the Internet of Things and Big Data analytics impact the education of learning-disabled students? A concept paper.” Big Data and Smart City (ICBDSC), 2016 3rd MEC International Conference on. IEEE, 2016. https://doi.org/10.1109/ICBDSC.2016.7460389

[38] Q.Z.Sheng, et al. "Ubiquitous RFID: Where are we?."Information Systems Frontiers 12.5 (2010): 485-490. https://doi.org/10.1007/s10796-009-9212-x

[39] D. Giusto, A. Iera, G. Morabito, L. Atzori (Eds.), "the Internet of Things", Springer, 2010. ISBN: 978-1-4419-1673-0. https://doi.org/10.1007/978-1-4419-1674-7

[40] M.C.Domingo, "An overview of the Internet of Things for people with disabilities.",Journal of Network and Computer Applications 35.2 (2012): 584-596 https://doi.org/10.1016/j.jnca.2011.10.015

[41] M.T.Sarıșş,"The Emergent Technological and Theoretical Paradigms in Education: The Interrelations of Cloud Computing (CC), Connectivism and Internet of Things (IoT)." Acta Polytechnica Hungarica 12.6 (2015): 161-179.

[42] A.Taamallah and M. Khemaja. "Providing pervasive Learning eXperiences by Combining Internet of Things and e-Learning standards/Proporcionar experiencias de aprendizaje ubicuo mediante la combinación de Internet de las Cosas y los estándares de eLearning." Education in the Knowledge Society16.4 (2015): 98. 